\title{
Increasing incidence of adenocarcinoma of the gastroesophageal junction and distal stomach in Canada - An epidemiological study from 1964 to 2002
}

\author{
Jeremy R Parfitt MD ${ }^{1}$, Zoran Miladinovic BSc $^{2}$, David K Driman MBChB ${ }^{1}$
}

\begin{abstract}
JR Parfitt, Z Miladinovic, DK Driman. Increasing incidence of adenocarcinoma of the gastroesophageal junction and distal stomach in Canada - An epidemiological study from 1964 to 2002. Can J Gastroenterol 2006;20(4):271-276.
\end{abstract}

BACKGROUND: The increasing incidence of esophageal and proximal gastric (cardia) adenocarcinoma and the decreasing incidence of distal gastric (antropyloric) adenocarcinoma has been documented in several populations. The aim of the present study was to examine incidence trends of these neoplasms in Ontario, Canada's most populous province, over a 39-year period.

METHODS: Analyses were based on data obtained from the Ontario Cancer Registry of Cancer Care Ontario. Number of cases and rates per 100,000 , age-adjusted to the 1996 Canadian standard, were obtained for all esophageal and gastric carcinoma cases reported between 1964 and 2002. Rates were grouped into five-year periods to analyze trends over the 39-year period. Point and 95\% CI estimates of average annual percentage change in incidence rates were calculated with a log-linear regression model.

RESULTS: The incidence of adenocarcinoma of the distal esophagus increased in men and women (average annual increase of $9.5 \%$ in men; $4.3 \%$ in women). The incidence of adenocarcinoma of the cardia increased in men and women (average annual increase of $7.3 \%$ in men; $5.8 \%$ in women). The incidence of antropyloric adenocarcinoma increased in men and women (average annual increase of $4.4 \%$ in men; $5.3 \%$ in women). The incidence of esophageal squamous cell carcinoma remained stable.

CONCLUSIONS: There has been a significant increase in the incidence of adenocarcinoma around the gastroesophageal junction in men over the 39-year study period. The increase in incidence of distal gastric adenocarcinoma is unexpected and may relate to a reclassification phenomenon, immigration trends in Ontario and a rising incidence of diffuse/signet ring cell adenocarcinoma.

Key Words: Adenocarcinoma; Epidemiology; Esophageal neoplasms; Gastric neoplasms

W orldwide, esophageal cancer is the sixth leading cause of cancer-related death, with squamous cell carcinoma and adenocarcinoma accounting for greater than $90 \%$ of these malignancies (1). Gastric cancer, $90 \%$ adenocarcinoma by histology, has a high mortality rate, accounting for more deaths worldwide than any other cancer except for lung cancer (2).
Incidence accrue du cancer de la jonction oesophago-gastrique et de l'extrémité distale de l'estomac au Canada : résultats d'une étude épidémiologique, de 1964 à 2002

CONTEXTE : L'augmentation de l'incidence du cancer de l'œsophage et de l'extrémité proximale de l'estomac (cardia) et la diminution de l'incidence du cancer de l'extrémité distale de l'estomac (antre pylorique) ont été établies dans plusieurs populations. La présente étude avait pour but d'examiner les tendances relatives à l'incidence de ces néoplasmes en Ontario, la province la plus populeuse au Canada, sur une période de 39 ans.

MÉTHODE : Les analyses ont été réalisées à partir de données obtenues du Registre d'inscription des cas de cancer de l'Ontario de l'Action Cancer Ontario. Le nombre de cas et les taux pour 100000 personnes, rectifiés selon l'âge d'après la norme canadienne de 1996, ont été obtenus pour tous les cas de cancer de l'œsophage et de l'estomac, signalés entre 1964 et 2002. Les taux ont été groupés en tranches de cinq ans pour permettre l'analyse des tendances sur la période de 39 ans. Les variations annuelles moyennes des taux d'incidence, estimées en points de pourcentage, selon un intervalle de confiance à $95 \%$, ont été calculées à l'aide d'un modèle de régression linéaire logarithmique.

RÉSULTATS : Il est ressorti des analyses une augmentation de l'incidence du cancer de la partie distale de l'oesophage chez les hommes et chez les femmes (augmentation annuelle moyenne de 9,5\% et de 4,3\% respectivement), du cancer du cardia chez les hommes et chez les femmes (augmentation annuelle moyenne de 7,3 \% et de 5,8 \% respectivement) et du cancer de l'antre pylorique chez les hommes et chez les femmes (augmentation annuelle moyenne de 4,4\% et de 5,3\% respectivement). Par contre, l'incidence du cancer squameux de l'œsophage est restée stable.

CONCLUSIONS : Il y a eu une augmentation significative de l'incidence de l'adénocarcinome autour de la jonction oesophago-gastrique chez les hommes, sur la période d'étude de 39 ans. Toutefois, l'augmentation de l'incidence du cancer de l'extrémité distale de l'estomac était imprévue et elle pourrait s'expliquer par un effet de reclassement, les tendances de l'immigration en Ontario et une incidence accrue de l'adénocarcinome diffus et de l'adénocarcinome à cellules en bague à chaton.

\footnotetext{
${ }^{1}$ Department of Pathology, London Health Sciences Centre; ${ }^{2}$ Department of Epidemiology and Biostatistics, University of Western Ontario, London, Ontario

Correspondence: Dr David K Driman, Department of Pathology, London Health Sciences Centre, 339 Windermere Road, London, Ontario N6A 5A5. Telephone 519-685-8500, fax 519-663-2930, e-mail ddriman@uwo.ca

Received for publication November 16, 2005. Accepted January 12, 2006
} 
incidence of these neoplasms in Ontario, Canada's most populous province, over a 39-year period.

\section{METHODS}

The Ontario Cancer Registry (OCR) provided the data for analysis. The OCR is the largest patient-specific, population-based cancer incidence registry in Canada (unpublished data). While no legal requirement exists for reporting cases, Cancer Care Ontario (CCO), which is responsible for the OCR, has a legal mandate to collect data on cancer patients. Registration is passive, relying on computer linkage to the four main data sources, including pathology reports submitted from private and hospital-based laboratories, hospital discharge summaries from all hospitals (through the Canadian Institute for Health Information), reports from the regional out-patient cancer centres and the Princess Margaret Hospital (Toronto, Ontario), as well as accumulated death certificates (unpublished data). Previous studies of the quality of data in the OCR have demonstrated completeness of case ascertainment ranging from $91 \%$ for melanoma to $98 \%$ for breast and gastrointestinal-related cancers (unpublished data). Historically, histological confirmation has been available for $85 \%$ of reported cancer cases. In general, cancer incidence analyses based on the date of diagnosis, rather than the date of reporting, offer a more accurate estimate of the rate of disease occurrence. The CCO case resolution system uses a set of rules to determine the date of diagnosis, such as considering the date of surgery or of specimen accessioning. This has not revealed significant lag time bias due to incongruent dates of diagnosis and reporting for esophageal and gastric cancers in Ontario.

The analysis includes all primary cancers of the esophagus, including tumours classified under International Classification of Diseases for Oncology (ICD-O) site codes 150.0 to 150.9 and stomach, including tumours classified under ICD-ninth revision (9) codes 151.0 to 151.9 (10). Upper, middle and lower esophageal cancers are classified under site codes 150.0, 150.1 and 150.2, respectively, while cardia, fundus, body, greater and lesser curve, antrum and pylorus gastric cancers, respectively, bear the site codes ranging from 151.1 to 151.6. ICD-O histology codes for esophageal cancers subclassify adenocarcinomas (ICD-O codes $814,816,819$ to 822,826 to 833,835 to 855,857 and 894 ) and squamous cell carcinomas (ICD-O codes 805 to 808 and 812 to 813). Gastric adenocarcinomas also have multiple possible ICD-O histology codes (8140 to 8384 or 8480 to 8490 ). Gastric adenocarcinoma can be subdivided histologically into glandular/intestinal and diffuse/signet ring cell types. The former is characterized by cohesive neoplastic cells that form glands, while the latter is characterized by discohesive neoplastic cells, usually with a signet ring morphology, that infiltrate diffusely and cause illdefined thickening of the stomach wall (sometimes called linitis plastica or leather-bottle stomach). Diffuse/signet ring cell gastric adenocarcinomas have the following ICD-O codes: 8145 (diffuse), 8490 (signet ring cell) and 8142 (linitis plastica) respectively.

Incidence rates are standardized to the 1996 Canadian population and are expressed as the number of new cases per 100,000 population per year. These rates are collapsed into five-year groups (except for the four-year period from 1999 to 2002) for trend analysis over the 39-year study period from 1964 to 2002. Change in annual percentages and associated 95\% CI are calculated by fitting a log-linear regression model to standardized incidence rates using the least squares method. The model takes the form $\log Y=a+b x$, where $Y$ is the estimated standardized incidence rate. The estimated annual percentage change is represented by the expression 100( $\left.\mathrm{e}^{\mathrm{b}}-1\right)$ and $95 \% \mathrm{CI}$ are represented by the expression $100\left(e^{b \pm t \alpha / 2 s}-1\right)$, where $b$ is assumed to be $t$-distributed, $s$ is the standard deviation of $\mathrm{b}$ and $\alpha$ is the level of significance (5\%). Annual rates of change that are greater than $-0.05 \%$ and less than $0.05 \%$ are reported as 0 . Statistical calculations were performed using the software SAS version 8.02 (SAS Institute Inc, USA).

\section{RESULTS}

The age-adjusted annual incidences and absolute case numbers for cancers of the esophagus and stomach occurring in Ontario men and women during the period from 1964 to 2002 are shown in Table 1. The incidence of squamous cell carcinoma in the distal and middle thirds of the esophagus remained stable among men and women (Figure 1A). The incidence of distal esophageal adenocarcinoma increased dramatically in men (Figure 1B). The annual rates per 100,000 population rose from 0.8 during 1979 to 1983 to 2.5 during 1999 to 2002, an increase of over $300 \%$. The corresponding number of cases rose from 140 to 569 . Although the incidence among women also increased, the absolute number of cases was much smaller over the study period than for men (Figure 1B).

The incidence of gastric cardia adenocarcinoma increased modestly in men (Figure 2A). The annual rates per 100,000 population rose from 2.5 during 1979 to 1983 to 3.3 during 1999 to 2002. The corresponding number of cases rose from 429 to 743 . The incidence of gastric antropyloric adenocarcinoma increased in men, although to a lesser degree than cardia cancers, with 315 cases during 1979 to 1983 rising to 477 cases during 1999 to 2002 (Figure 2B). There was a corresponding increase in both glandular/intestinal and diffuse/signet ring cell varieties of adenocarcinoma occurring in the distal stomach during the study period. While the absolute numbers of the glandular/intestinal type were greater than the diffuse/signet ring cell type (369 cases of glandular/intestinal versus 108 cases of diffuse/signet ring cell during 1999 to 2002), the rate of rise of the latter was higher (annual percentage change was 5.4\% for diffuse/signet ring cell versus $3.5 \%$ for glandular/intestinal) (Table 2). Interestingly, by 2002, the annual number of new cases of gastric cardia adenocarcinoma in men almost equaled the number of cases of noncardia gastric adenocarcinoma. While the incidence of proximal and distal gastric adenocarcinomas also rose among women, rates remained much lower than among men (Figure 2A). The incidence of gastric adenocarcinoma not otherwise specified (NOS) decreased over the study period, with 1346 cases during 1979 to 1983 decreasing to 644 cases during 1999 to 2002 (men and women combined) (Table 1). This decrease in nonspecific reporting pertained mainly to glandular/intestinal histological types, because incidence of adenocarcinoma NOS with diffuse/signet ring cell histology showed no appreciable trend over the study period (data not shown). Other nonspecific categories, such as adenocarcinoma of lesser or greater curve NOS, contained too few cases to interpret trend analyses (data not shown).

\section{DISCUSSION}

The results show a marked increase in the incidence of esophageal adenocarcinoma over the past 25 years, such that adenocarcinoma has become the dominant form of esophageal carcinoma among men living in Ontario (Figure 2B). Rates of gastric cardia adenocarcinomas have also been increasing, although less dramatically, such that the rates of cardia and noncardia gastric cancer are nearly equivalent. Studies have 
Age-adjusted annual incidences and absolute case numbers for cancers of the esophagus and stomach, 1964 to 2002

\begin{tabular}{|c|c|c|c|c|c|c|c|c|c|c|c|c|}
\hline \multirow[b]{2}{*}{ Carcinoma subtype } & \multirow[b]{2}{*}{ Sex } & \multicolumn{8}{|c|}{ Incidence rates (number of new cases) } & \multirow[b]{2}{*}{$A C$} & \multirow[b]{2}{*}{$95 \% \mathrm{Cl}$} & \multirow[b]{2}{*}{$\mathbf{P}$} \\
\hline & & 1964-1968 & $1969-1973$ & $1974-1978$ & 1979-1983 & 1984-1988 & $1989-1993$ & 1994-1998 & 1999-2002 & & & \\
\hline \multicolumn{13}{|l|}{ Stomach: Adenocarcinoma } \\
\hline Pylorus + pyloric antrum & $\mathrm{F}$ & $0.1(23)$ & $0.2(62)$ & $0.3(101)$ & $0.6(251)$ & $0.6(283)$ & $0.6(346)$ & $0.7(411)$ & $0.5(299)$ & 5.3 & (3.4 to 7.1$)$ & $<0.0001$ \\
\hline Fundus + body & M & $0.0(11)$ & $0.1(21)$ & $0.1(42)$ & $0.5(156)$ & $0.5(202)$ & $0.6(240)$ & $0.5(254)$ & $0.6(241)$ & 5.3 & $(3.6$ to 7.0$)$ & $<0.0001$ \\
\hline Fundus + body & $\mathrm{F}$ & $0.0(6)$ & $0.0(4)$ & $0.1(21)$ & $0.2(78)$ & $0.2(90)$ & $0.2(112)$ & $0.3(195)$ & $0.3(150)$ & 5.0 & (3.5 to 6.6$)$ & $<0.0001$ \\
\hline Lesser + greater & $\mathrm{F}$ & $0.1(16)$ & $0.1(29)$ & $0.2(72)$ & $0.5(190)$ & $0.3(134)$ & $0.4(206)$ & $0.3(179)$ & $0.2(119)$ & 3.8 & (2.1 to 5.4$)$ & $<0.0001$ \\
\hline Cardia & M & $0.3(35)$ & $0.8(117)$ & $1.5(235)$ & $2.5(429)$ & $2.8(553)$ & $3.4(772)$ & $3.4(854)$ & $3.3(743)$ & 7.3 & (5.8 to 8.8 ) & $<0.0001$ \\
\hline Cardia & $\mathrm{F}$ & $0.1(9)$ & $0.2(40)$ & $0.4(70)$ & $0.5(115)$ & $0.6(152)$ & $0.7(197)$ & $0.7(214)$ & $0.7(188)$ & 5.8 & $(4.2$ to 7.4$)$ & $<0.0001$ \\
\hline NOS & M & $5.0(619)$ & $5.0(671)$ & $6.8(990)$ & $5.1(821)$ & $5.3(965)$ & $3.7(771)$ & $2.3(542)$ & $1.8(390)$ & -3.0 & $(-3.8$ to -2.1$)$ & $<0.001$ \\
\hline NOS & $\mathrm{F}$ & $2.4(332)$ & $2.2(335)$ & $2.9(536)$ & $2.5(525)$ & $2.5(614)$ & $1.7(487)$ & $1.1(357)$ & $0.9(254)$ & -2.7 & $(-3.5$ to -1.9$)$ & $<0.001$ \\
\hline Distal third & $\mathrm{F}$ & $0.0(0)$ & $0.0(0)$ & $0.0(1)$ & $0.1(24)$ & $0.2(38)$ & $0.2(62)$ & $0.3(88)$ & $0.3(88)$ & 4.3 & (2.2 to 6.6 ) & 0.0004 \\
\hline Middle third & M & $0.0(0)$ & $0.0(0)$ & $0.0(0)$ & $0.1(15)$ & $0.1(22)$ & $0.2(42)$ & $0.2(55)$ & $0.2(49)$ & 4.0 & (1.8 to 6.2 ) & 0.0009 \\
\hline Middle third & $\mathrm{F}$ & $0.0(0)$ & $0.0(0)$ & $0.0(0)$ & $0.0(8)$ & $0.0(5)$ & $0.1(14)$ & $0.1(21)$ & $0.1(15)$ & - & - & - \\
\hline Upper third & M & $0.0(0)$ & $0.0(0)$ & $0.0(0)$ & $0.0(3)$ & $0.0(10)$ & $0.0(8)$ & $0.1(12)$ & $0.1(15)$ & - & - & - \\
\hline Upper third & $\mathrm{F}$ & $0.0(0)$ & $0.0(0)$ & $0.0(0)$ & $0.0(1)$ & $0.0(4)$ & $0.0(4)$ & $0.0(3)$ & $0.0(4)$ & - & - & - \\
\hline \multicolumn{13}{|l|}{ Esophagus: SCC } \\
\hline Distal third & M & $0.0(0)$ & $0.0(3)$ & $0.1(13)$ & $0.9(147)$ & $1.0(186)$ & $0.9(187)$ & $0.7(177)$ & $0.8(171)$ & 3.5 & (0.45 to 6.6$)$ & 0.026 \\
\hline Distal third & $\mathrm{F}$ & $0.0(4)$ & $0.0(2)$ & $0.1(10)$ & $0.5(104)$ & $0.4(92)$ & $0.5(132)$ & $0.3(114)$ & $0.4(104)$ & 3.1 & (0.93 to 5.4 ) & 0.007 \\
\hline Middle third & M & $0.0(1)$ & $0.0(3)$ & $0.0(10)$ & $1.0(176)$ & $1.1(219)$ & $1.0(228)$ & $1.0(221)$ & $1.0(129)$ & 1.7 & $(-1.9$ to 5.4$)$ & 0.342 \\
\hline Middle third & $\mathrm{F}$ & $0.0(1)$ & $0.0(5)$ & $0.0(9)$ & $0.5(106)$ & $0.5(116)$ & $0.5(138)$ & $0.6(170)$ & $0.4(113)$ & 2.1 & (0.15 to 4.2$)$ & 0.003 \\
\hline
\end{tabular}

AC Annual change; F Female; M Male; NOS Not otherwise specified; SCC Squamous cell carcinoma

reported similar trends in the United States, United Kingdom, Scotland, Scandinavia, France, Switzerland, Australia and New Zealand (3-9,11-13).

Proper interpretation of data obtained from cancer registries such as the $\mathrm{CCO}$ must consider several possible confounding factors. Because the level of ascertainment for cancer cases in Ontario is nearly 100\%, completeness of data should not be a source of bias. In recent years, the CCO has reported a possible over-reporting of $5 \%$ to $6 \%$, which may slightly inflate the rising cancer trends in this study (unpublished data). Although the rate of histological verification has been reported to be $85 \%$ for many years, some subcategories of incidence data from 1964 to 1978 show increases beyond what could be reasonably expected over that time frame. As such, interpretation of data from the 1960s and early 1970s remains guarded and to avoid bias, we have confined our interpretations mainly to observations made from 1979 through to 2002.

Changes in classification tendencies for esophageal and gastric cancers could be another source of possible error. In the past, adenocarcinomas around the gastroesophageal junction were more often classified as gastric in origin; hence, increasing awareness of distal esophageal adenocarcinomas could lead to artifactual increased incidence of the latter. Also, some authors have criticized the ICD-9 site code classification system, which lacks the power to histologically subclassify and does not allow for distinction between distal esophageal and gastric cardia adenocarcinomas (14). These authors purport that subsequent use of the ICD-O system, which employs both site and histology codes with separate codes for esophageal and gastric cardia adenocarcinoma, may explain the increase in esophageal adenocarcinoma (14). However, this cannot fully explain the rising trend of esophageal adenocarcinoma in Ontario, because a concomitant decrease in gastric cardia adenocarcinoma has not occurred, which would normally be expected in the context of a reclassification phenomenon. Further, a new approach to classification of gastroesophageal junction cancers should affect men and women equally, yet the incidence of distal esophageal and cardia adenocarcinoma (separately and combined) increased more dramatically in men than women (Figures 1B, 2B). Our analysis attempts to minimize the shortcomings of the ICD-9 system by employing ICD-O site and histology codes for esophageal cancers and combining ICD-O histology codes with ICD-9 sites codes for gastric cancers.

Recently, Engel et al (15) analyzed the population attributable risks for esophageal and gastric cancers. In their study, more than one-half of gastroesophageal junction adenocarcinomas could be explained by smoking or body mass index. Some authors believe that cigarette smoking makes an early carcinogenic contribution to the pathogenesis of esophageal squamous cell carcinoma, while adenocarcinomas arise through a late promotional effect of smoking (3). Thus, the high prevalence 


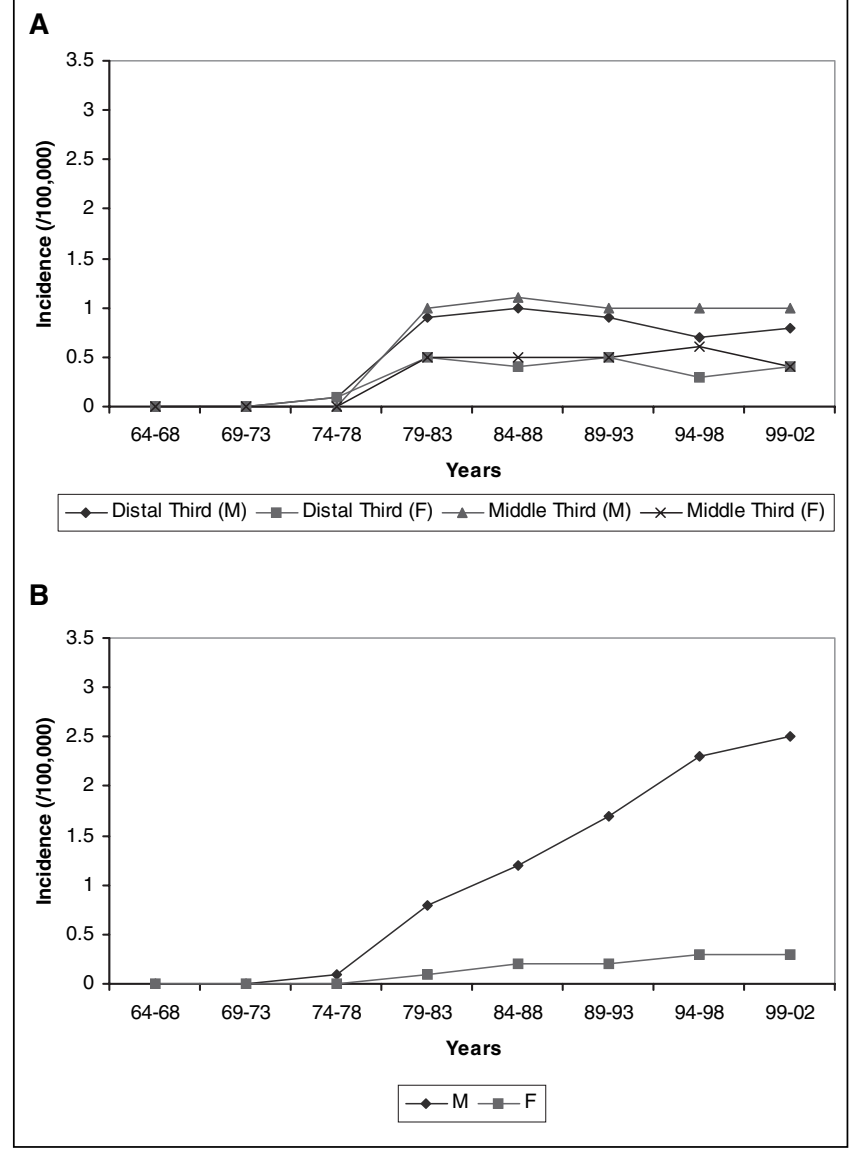

Figure 1) A Incidence of esophageal squamous cell carcinoma - distal versus middle thirds. B Incidence of esophageal adenocarcinoma distal third. F Female; M Male

of cigarette smoking in the first one-half of the 20th century may partly explain the rising incidence of esophageal adenocarcinoma, through a delayed effect of smoking. Birkett (16), using data from the 1990 Ontario Health Survey, showed a steady drop in smoking prevalence among men between 1940 and 1975 (16). While smoking increased in women until 1960, the trend was toward decreasing prevalence and increasing cessation of smoking in subsequent decades. This may explain the decreasing trends in esophageal squamous cell carcinoma, which follows smoking trends more immediately because of an early carcinogenic effect of the latter. While the proportion of Canadians who currently smoke has decreased markedly since the 1960s, teen smoking rates increased in the 1990s and recent data suggest that tobacco use among young adults remains high at $30 \%(17,18)$. This may be a harbinger of further increases in esophageal cancer in the future.

Given the strong association between body mass index and gastroesophageal reflux disease, some authors have suggested that the growing epidemic of obesity in North American society may partly explain the trend to increasing incidence of esophageal adenocarcinoma $(3,19)$. The presumed mechanism includes increasing intra-abdominal pressure leading to gastroesophageal reflux disease and in due course, intestinal metaplasia, which is the key cancer precursor. Katzmarzyk and Ardern (20) recently reported increasing obesity trends across Canada, especially in eastern provinces. Between 1985 and 2000, the population-attributable risk and annual number of

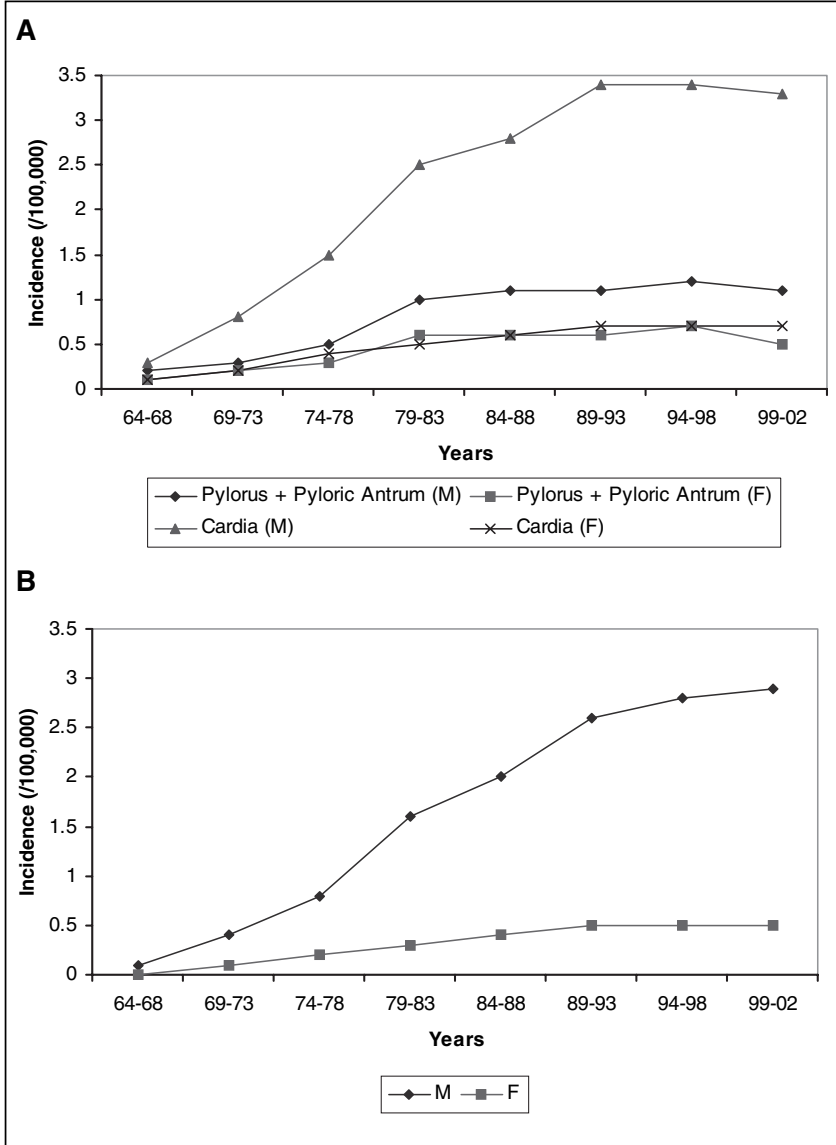

Figure 2) A Incidence of gastric adenocarcinoma - pylorus + pyloric antrum versus cardia. B Incidence of esophageal adenocarcinoma distal third + gastric cardia. F Female; M Male

deaths related to obesity nearly doubled in Canada. Thus, obesity appears to be an important culprit behind the growing Canadian epidemic of esophageal adenocarcinoma.

While Helicobacter pylori infection is an established risk factor for gastric adenocarcinoma, some authors have noted the temporal coincidence of falling $H$ pylori prevalence and rising incidence of esophageal adenocarcinoma $(5,21,22)$. $\mathrm{H}$ pylori leads to gastric cancer through chronic gastritis, atrophy, intestinal metaplasia and dysplasia, with the antrum being at greatest risk. CagA virulent strains are particularly carcinogenic. Paradoxically, the decreased intragastric acidity associated with $\mathrm{H}$ pylori may be protective against gastroesophageal reflux and its sequelae, including esophageal adenocarcinoma, the most dreaded complication of gastroesophageal reflux disease $(21,22)$. In Canada, as in the United States and other countries, increasing $\mathrm{H}$ pylori eradication therapy has diminished the prevalence of this microorganism, ironically eradicating a possible protective factor for gastroesophageal junction cancer in the process.

Several authors have suggested that esophageal and gastric cardia adenocarcinomas show sufficient epidemiological and pathogenetic overlap to be considered a single neoplastic entity $(4,5)$. Because accurate clinical and pathological classification of gastroesophageal junction tumours can, at times, be problematic, the idea of grouping these cancers as a single topographic entity may seem attractive. However, although both neoplasms have been rapidly increasing in incidence, predominantly occurring 
Age-adjusted annual incidences and absolute case numbers for glandular/intestinal and diffuse/signet ring cell types of adenocarcinoma of the stomach, 1964 to 2002

\begin{tabular}{|c|c|c|c|c|c|c|c|c|c|c|c|c|}
\hline \multirow[b]{2}{*}{ Carcinoma subtype } & \multirow[b]{2}{*}{ Sex } & \multicolumn{8}{|c|}{ Incidence rates (number of new cases) } & \multirow[b]{2}{*}{ AC } & \multirow[b]{2}{*}{$95 \% \mathrm{Cl}$} & \multirow[b]{2}{*}{$\mathbf{P}$} \\
\hline & & 1964-1968 & $1969-1973$ & 1974-1978 & $1979-1983$ & 1984-1988 & 1989-1993 & 1994-1998 & 1999-2002 & & & \\
\hline \multicolumn{13}{|l|}{ Pylorus + pyloric antrum } \\
\hline Diffuse/signet ring cell & $\mathrm{M}$ & $0.0(0)$ & $0.0(0)$ & $0.0(4)$ & $0.1(30)$ & $0.1(54)$ & $0.2(91)$ & $0.2(107)$ & $0.2(108)$ & 5.4 & $(2.0$ to 9.0$)$ & 0.002 \\
\hline Glandular/intestinal & $\mathrm{M}$ & $0.2(54)$ & $0.3(84)$ & $0.5(149)$ & $0.8(285)$ & $0.9(343)$ & $0.9(401)$ & $0.9(453)$ & $0.8(369)$ & 3.5 & $(1.9$ to 5.1$)$ & $<0.0001$ \\
\hline Diffuse/signet ring cell & $\mathrm{F}$ & $0.0(0)$ & $0.0(0)$ & $0.0(2)$ & $0.1(36)$ & $0.1(47)$ & $0.1(82)$ & $0.2(112)$ & $0.1(76)$ & 2.7 & $(-1.2$ to 6.8$)$ & 0.173 \\
\hline Glandular/intestinal & $\mathrm{F}$ & $0.1(23)$ & $0.2(62)$ & $0.3(110)$ & $0.5(215)$ & $0.5(237)$ & $0.4(264)$ & $0.4(299)$ & $0.4(223)$ & 4.2 & $(2.4$ to 6.0$)$ & $<0.0001$ \\
\hline \multicolumn{13}{|l|}{ Fundus + body } \\
\hline Diffuse/signet ring cell & M & $0.0(0)$ & $0.0(1)$ & $0.0(0)$ & $0.0(12)$ & $0.1(22)$ & $0.1(35)$ & $0.1(45)$ & $0.1(52)$ & 4.4 & $(1.6$ to 7.4$)$ & 0.003 \\
\hline Glandular/intestinal & $\mathrm{M}$ & $0.0(11)$ & $0.1(20)$ & $0.1(42)$ & $0.4(144)$ & $0.5(180)$ & $0.5(205)$ & $0.4(209)$ & $0.4(189)$ & 4.6 & $(2.9$ to 6.2$)$ & $<0.0001$ \\
\hline Diffuse/signet ring cell & $\mathrm{F}$ & $0.0(0)$ & $0.0(0)$ & $0.0(2)$ & $0.0(13)$ & $0.0(15)$ & $0.0(24)$ & $0.1(49)$ & $0.1(43)$ & 4.8 & (2.4 to 7.3$)$ & 0.0002 \\
\hline Glandular/intestinal & $\mathrm{F}$ & $0.0(6)$ & $0.0(4)$ & $0.0(19)$ & $0.1(65)$ & $0.1(75)$ & $0.1(88)$ & $0.2(146)$ & $0.2(107)$ & 4.0 & $(2.5$ to 5.6$)$ & $<0.0001$ \\
\hline \multicolumn{13}{|l|}{ Lesser + greater curve } \\
\hline Diffuse/signet ring cell & $\mathrm{M}$ & $0.0(0)$ & $0.0(0)$ & $0.0(4)$ & $0.1(30)$ & $0.0(19)$ & $0.1(42)$ & $0.1(50)$ & $0.1(37)$ & 0.0 & $(-3.1$ to 3.2$)$ & 0.997 \\
\hline Glandular/intestinal & $\mathrm{M}$ & $0.1(28)$ & $0.2(53)$ & $0.5(155)$ & $0.8(269)$ & $0.6(239)$ & $0.5(225)$ & $0.5(250)$ & $0.4(193)$ & 4.3 & (2.5 to 6.2$)$ & $<0.0001$ \\
\hline Diffuse/signet ring cell & $\mathrm{F}$ & $0.0(0)$ & $0.0(0)$ & $0.0(4)$ & $0.1(27)$ & $0.0(16)$ & $0.1(50)$ & $0.1(48)$ & $0.1(48)$ & 2.7 & $(0.1$ to 5.4$)$ & 0.044 \\
\hline Glandular/intestinal & $\mathrm{F}$ & $0.1(16)$ & $0.1(29)$ & $0.2(68)$ & $0.4(163)$ & $0.2(118)$ & $0.3(156)$ & $0.2(131)$ & $0.1(81)$ & 2.4 & (0.7 to 4.0$)$ & 0.005 \\
\hline
\end{tabular}

AC Annual change; F Female; M Male

in older white men living in industrialized countries, our analysis suggests that these cancers may have different epidemiological influences. Notably, the increasing incidence of adenocarcinoma of the gastric cardia reached a plateau in the mid 1980s and has since remained stable (Figure 2A). Conversely, the incidence of esophageal adenocarcinoma continued to rise through 2002, suggesting that different epidemiological and etiological factors influence these cancers (Figure 1B). Recently, Kubo and Corley (23) demonstrated that esophageal and cardia adenocarcinoma vary markedly by ethnicity in the United States. While Caucasians had the highest incidence rates for both adenocarcinoma sites, the rates for cardia cancer were more similar among different ethnicities. Further, a continuing rise in incidence rates was seen only for esophageal adenocarcinoma and only among Caucasians. Ethnicity was not analyzed in the present study because the OCR does not collect ethnicity data. Other authors have drawn similar conclusions and have further noted that gastroesophageal reflux disease and obesity remain to be firmly established as risk factors for gastric cardia cancer, while carcinogens such as $\mathrm{H}$ pylori and $\mathrm{N}$-nitroso compounds are positively associated with adenocarcinoma of the gastric cardia rather than esophagus (14).

Gastric cancer has been decreasing in most countries in recent decades, in both low- and high-incidence locales, parallelling the movement toward $\mathrm{H}$ pylori eradication (2). Surprisingly, the incidence of gastric antropyloric adenocarcinoma increased in both men and women in Ontario over the study period. While further elucidation is required, reclassification phenomenon, Canadian immigration trends and increasing diffuse/signet ring cell adenocarcinoma may each offer a partial explanation. Over the study period, there was a significant decrease in gastric adenocarcinoma of no specified location, with 1346 cases during 1979 to 1983 decreasing to 644 cases during 1999 to 2002 (men and women combined) (Table 1). Because awareness of gastric cardia adenocarcinoma has increased over the past 50 years, physicians may have been more likely to classify gastric cancers as antropyloric, rather than leaving the location unspecified, so as to distinguish distal from proximal gastric cancer. Because such a phenomenon seems equally likely to affect reporting of both gastric cardia and antropyloric carcinomas, this may have contributed to apparently rising incidences of cancers at both sites.

Levels of immigration in Canada in the 1990s were higher than previously recorded over a number of decades. Annual immigration levels rose from 85,000 in 1985 to approximately 200,000 per year during the 1990s (24). Further, since the 1970s, an increasing number of immigrants have been from non-European countries, in particular from East Asia. The number of immigrants from East Asia has increased from 36,365 during 1961 to 1970 to 423,235 during 1991 to 2001 (Figure 3) (25). Eastern Europe, the Middle East, South and Central America have also been increasingly important immigrant contributors (Figure 3). Not only were immigrants more likely than the Canadian-born to live in Canada's major urban centres, namely Toronto, Vancouver and Montreal, but Ontario attracted the majority of immigrants (24). The International Agency for Research on Cancer data for 1996 showed the highest risk areas for gastric adenocarcinoma included Japan and China, followed by South and Central America $(2,26,27)$. Noncardia cancer accounts for most of the geographic variation; gastric cardia cancer, which has a more uniform geographic distribution, accounts for less than $5 \%$ of gastric cancer in Japan (2). While ethnic groups who have migrated from high- to lowincidence countries have an overall risk intermediate between their native land and their new country, first-generation migrants tend to maintain their high risk (27). While the OCR does not collect ethnicity data, the unique trend to increasing distal gastric cancer in Ontario may relate to its increasing population of immigrants from high-incidence regions for this cancer.

Finally, the incidence of antropyloric diffuse/signet ring cell adenocarcinoma increased over the study period, offering a further explanation for rising distal gastric cancers in Ontario. These results are similar to those of Henson et al (28), who recently reported a trend to increasing diffuse types of gastric adenocarcinoma in the United States (the signet ring cell variety 


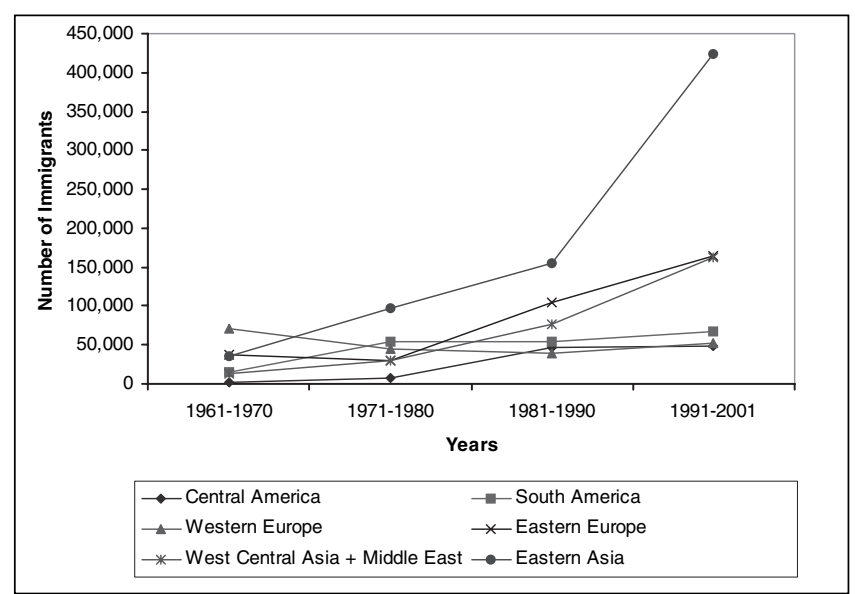

Figure 3) Immigration to Canada - 1961 to 2001

in particular). Sidoni (29) also reported a trend to increasing diffuse/signet ring cell adenocarcinomas in the stomach, further noting this increase to have occurred in the middle and distal locations. Most authors believe that diffuse/signet ring cell adenocarcinoma differs from the glandular/intestinal variety

\section{REFERENCES}

1. Enzinger PC, Mayer RJ. Esophageal cancer. N Engl J Med 2003;349:2241-52.

2. Kelley JR, Duggan JM. Gastric cancer epidemiology and risk factors. J Clin Epidemiol 2003;56:1-9.

3. Devesa SS, Blot WJ, Fraumeni JF Jr. Changing patterns in the incidence of esophageal and gastric carcinoma in the United States. Cancer 1998;83:2049-53.

4. Blot WJ, Devesa SS, Kneller RW, Fraumeni JF Jr. Rising incidence of adenocarcinoma of the esophagus and gastric cardia. JAMA 1991;265:1287-9.

5. Sihvo EIT, Salminen JT, Ramo OJ, Salo JA. The epidemiology of esophageal adenocarcinoma: Has the cancer of gastric cardia an influence on the rising incidence of esophageal adenocarcinoma? Scand J Gastroenterol 2000;10:1082-6.

6. Powell J, McConkey CC. Increasing incidence of adenocarcinoma of gastric cardia and adjacent sites. Br J Cancer 1990;62:440-3.

7. Hansen S, Wiig JN, Giercksky KE, Tretli S. Esophageal and gastric carcinoma in Norway 1958-1992: Incidence time trend variability according to morphological subtypes and organ subsites. Int J Cancer 1997;71:340-4.

8. Hansen LE, Sparen P, Nyren O. Increasing incidence of both major histological types of esophageal carcinomas among men in Sweden. Int J Cancer 1993;54:402-7.

9. Lord RVN, Law MG, Ward RL, Giles GG, Thomas RJS, Thursfield V. Rising incidence of esophageal adenocarcinoma in men in Australia. J Gastroenterol Hepatol 1998;13:356-62.

10. World Health Organization. International classification of diseases for oncology, $2^{\text {nd }}$ edn. Geneva: WHO, 1990.

11. McKinney A, Sharp L, Macfarlane GJ, Muir CS. Esophageal and gastric cancer in Scotland 1960-90. Br J Cancer 1995;71:411-5.

12. Tuyns AJ. Esophageal cancer in France and Switzerland: Recent time trends. Eur J Cancer Prev 1992;1:275-8.

13. Armstrong RW, Borman B. Trends in incidence rates of adenocarcinoma of the esophagus and gastric cardia in New Zealand, 1978-1992. Int J Epidemiol 1996;25:941-7.

14. el-Serag HB. The epidemic of esophageal adenocarcinoma. Gastroenterol Clin North Am 2002;31:421-40.

15. Engel LS, Chow WH, Vaughan TL, et al. Population attributable risks of esophageal and gastric cancers. J Natl Cancer Inst 2003;95:1404-13.

16. Birkett NJ. Trends in smoking by birth cohort for births between 1940 and 1975: A reconstructed cohort analysis of the 1990 Ontario Health Survey. Prev Med 1997;26:534-41. epidemiologically and pathogenetically. While the underlying mechanisms that cause diffuse/signet ring cell adenocarcinoma remain poorly understood, it is thought to be less related to smoking and consumption of fruits and vegetables than glandular/intestinal gastric cancer. Further, the former arises from a multistep genetic carcinogenesis pathway independent of the atrophic gastrointestinal metaplasia-dysplasia sequence that characterizes the latter.

\section{SUMMARY}

There has been a significant increase in the incidence of adenocarcinomas around the gastroesophageal junction in males over the 39-year study period, as reported in other populations. Smoking and obesity trends in Ontario over the first and latter parts of the 20th century, respectively, appear to have played a significant role. While the increasing incidence of distal gastric adenocarcinomas may be partly related to a reclassification phenomenon, Ontario's unique immigration trends and a rising incidence of diffuse/signet ring cell adenocarcinomas may offer further explanations.

ACKNOWLEDGEMENTS: The authors thank Jeff Bowler and Carole Herbert at Ontario Cancer Registry/Cancer Care Ontario (OCR/CCO) for their help in obtaining registry data and information about OCR/CCO.
17. Stephens M, Siroonian J. Smoking prevalence, quit attempts and successes. Health Reports (Statistics Canada) 1998;9:31-37.

18. Spurgeon D. Canada's teenagers less likely to smoke now than in 1999. BMJ 2004:329:420.

19. Chow WH, Blot WJ, Vaughan TL, et al. Body mass index and risk of adenocarcinomas of the esophagus and gastric cardia. J Natl Cancer Inst 1998;90:150-5.

20. Katzmarzyk PT, Ardern CI. Overweight and obesity mortality trends in Canada, 1985-2000. Can J Public Health 2004; 95:16-20.

21. Chow WH, Blaser MJ, Blot WJ, et al. An inverse relation between cagA+ strains of Helicobacter pylori infection and risk of esophageal and gastric cardia carcinoma. Cancer Res 1998;58:588-90.

22. Richter JE, Falk GW, Vaezi MF. Helicobacter pylori and gastroesophageal reflux disease: The bug may not be all bad. Am J Gastroenterol 1998;93:1800-2.

23. Kubo A, Corley DA. Marked multi-ethnic variation of esophageal and gastric cardia carcinomas within the United States. Am J Gastroenterol 2004;99:582-8.

24. Statistics Canada. Canada's ethnocultural portrait: The changing mosaic. <www12.statcan.ca/english/census01/products/analytic/ companion/etoimm/contents.cfm $>($ Version curent at February 14, 2006).

25. Statistics Canada. Immigrant status and period of immigration (10A) and place of birth of respondent (260) for immigrants and non-permanent residents for Canada, provinces, territories, census metropolitan areas and census agglomerations, 2001 census-20\% Sample Data-Immigration and Citizenship. $<$ www12.statcan.ca/english/census01/products/standard/themes/in dex.cfm> (Version current at February 14, 2006).

26. Parkin DM, Whelan SL, Ferlay J, Teppo L, Thomas DB. Cancer incidence in five continents, vol VII. Lyon: International Agency for Research on Cancer, 1997:822-3.

27. Crew KD, Neugut AI. Epidemiology of upper gastrointestinal malignancies. Semin Oncol 2004;31:450-64.

28. Henson DE, Dittus C, Younes M, Nguyen H, Albores-Saavedra J. Differential trends in the intestinal and diffuse types of gastric carcinoma in the United States, 1973-2000. Increase in the signet ring cell type. Arch Pathol Lab Med 2004;128:765-70.

29. Sidoni A. Differential trends in the intestinal and diffuse types of gastric carcinoma. Arch Pathol Lab Med 2005;129:290. 


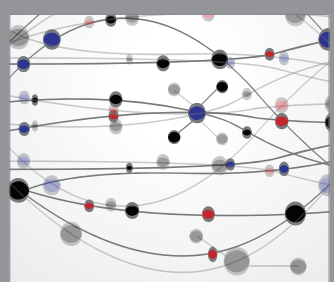

The Scientific World Journal
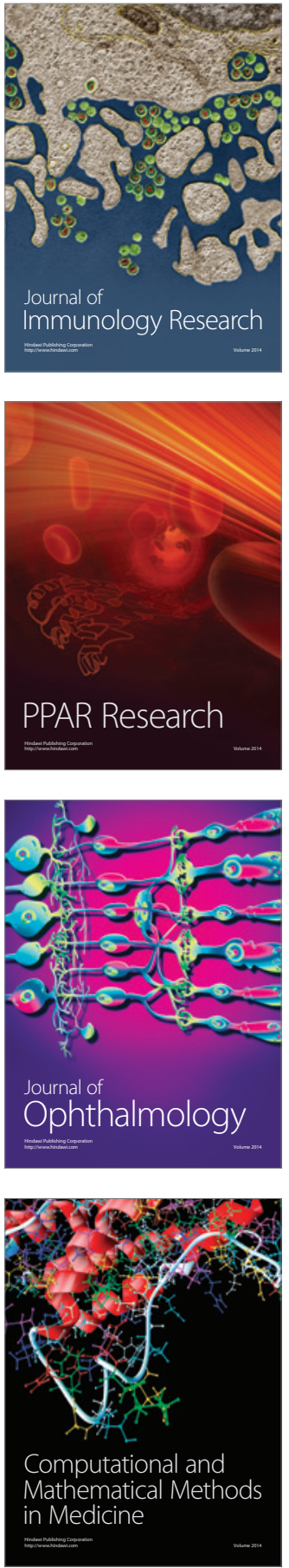

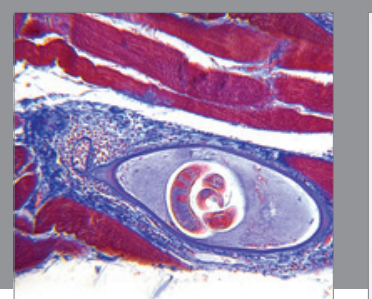

Gastroenterology Research and Practice

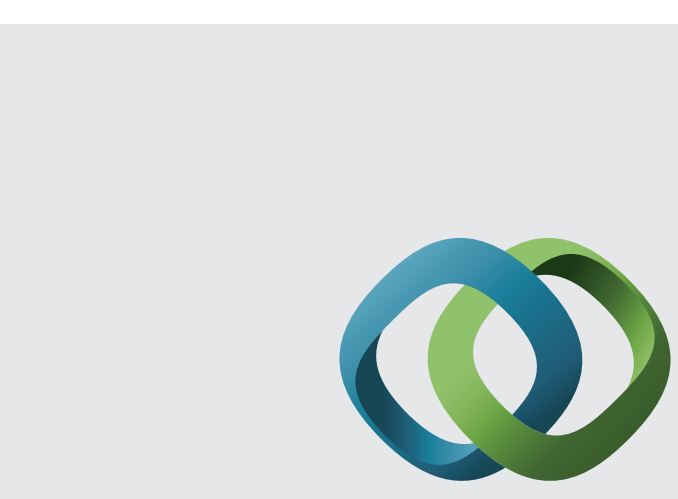

\section{Hindawi}

Submit your manuscripts at

http://www.hindawi.com
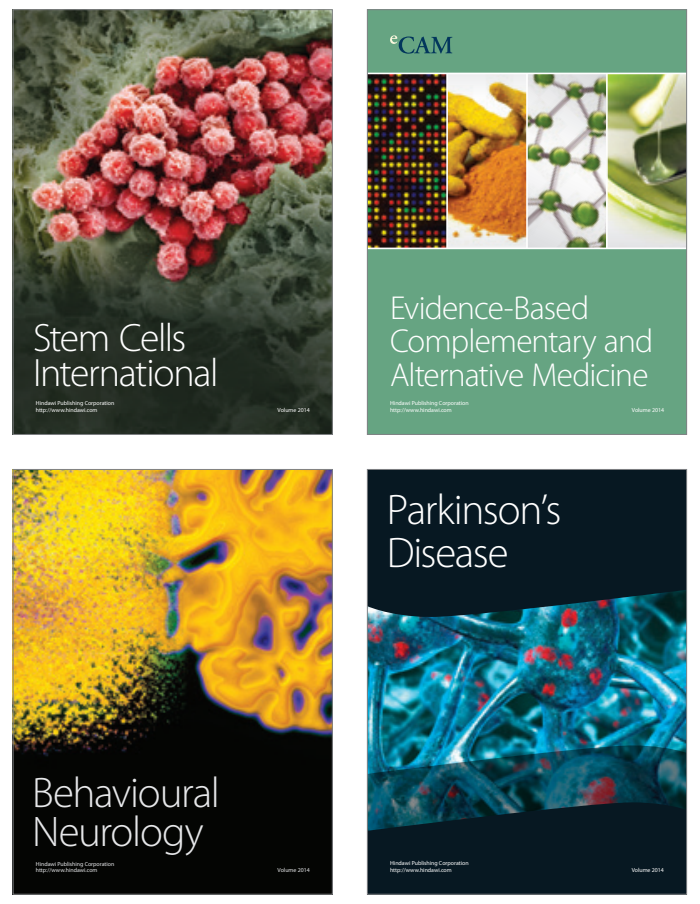
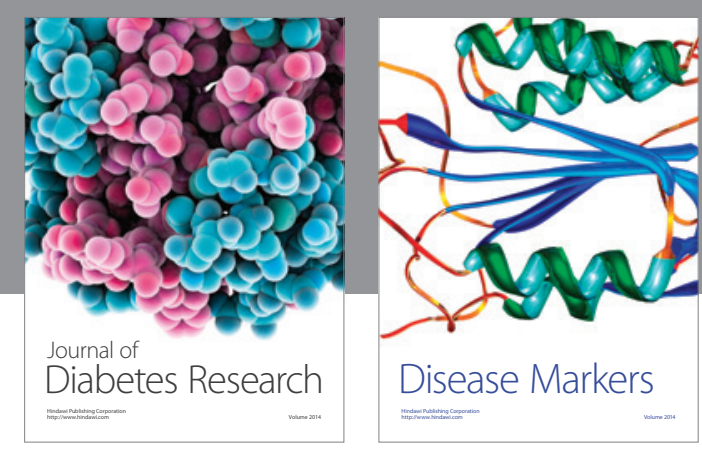

Disease Markers
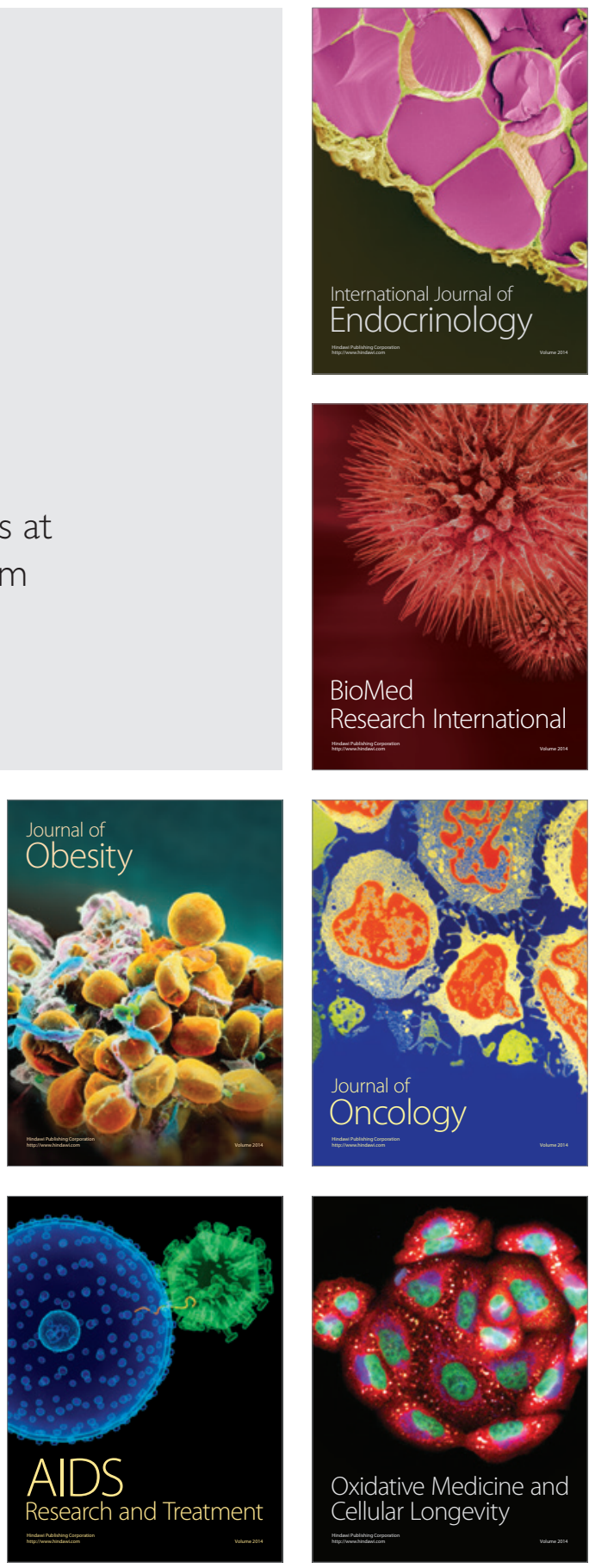